\title{
Cost-Utility Analysis of Biologic Therapies to Treat Chronic Plaque Psoriasis in Italy: The Importance of Using Updated and Adequate Social Tariffs to Calculate Quality-Adjusted Life-Years
}

\author{
Luciana Scalone $\cdot$ Paolo A. Cortesi
}

Published online: 30 January 2015

(c) Springer International Publishing Switzerland 2015

Spandonaro et al. [1] conducted an interesting cost-utility analysis to estimate the incremental cost/QALY (qualityadjusted life-year) ratio of biologic therapy for the treatment of chronic plaque psoriasis, adopting the perspective of the Italian National Health Service. The use of QALYs in the analysis allowed the calculation to include a parameter of effects measured in terms of health-related quality of life (HR-QOL), which is a component of health that is significantly compromised in patients with chronic plaque psoriasis.

It is not clear from their paper which social tariffs the authors used to obtain the utility indexes necessary to estimate QALYs. The authors collected HR-QOL data with the generic instrument EQ-5D-3L; hence, the Italian-specific social tariffs published in 2013 by Scalone et al. [2] are appropriate for converting the participants' responses into utility indexes. Previously, when a specific value set for Italy was missing, UK or Spanish sets were used to conduct health economic evaluations for the Italian healthcare system. However, comparisons of different national value sets have underlined the existence of differences across countries and the importance of assessing utilities that are country specific. The utility indexes obtained with the Italian social tariffs estimated in the paper published in 2013 are systematically higher than those obtained with the UK and Spanish algorithms

L. Scalone $(\square) \cdot$ P. A. Cortesi

Research Centre on Public Health (CESP),

Department of Statistics and Quantitative Methods,

University of Milano-Bicocca, Villa Serena,

Via Pergolesi 33, 20052 Monza, Italy

e-mail: luciana.scalone@unimib.it

L. Scalone · P. A. Cortesi

CHARTA Foundation, Milan, Italy established many years ago [3]: the mean (maximum) absolute differences correspond to $0.296(0.551)$ with the UK tariffs and $0.301(0.506)$ with the Spanish tariffs. Because the highest limit of the utility index corresponds to 1, higher utility indexes and consequently QALYs could potentially generate lower QALY differences (gains) between the two treatment options. Lower QALY gains would potentially generate a higher incremental cost/ QALY ratio, which could be relevant when addressing decision makers' willingness to pay.

Since the Italian-specific social tariffs were published a few months before publication of the paper by Spandonaro et al., it is relevant to decision makers that the authors clarify which social tariffs they used, and, if possible, provide updated and more appropriate values from the currently available data.

\section{References}

1. Spandonaro F, Ayala F, Berardesca E, Chimenti S, Girolomoni G, Martini P, et al. The cost effectiveness of biologic therapy for the treatment of chronic plaque psoriasis in real practice settings in Italy. BioDrugs. 2014;28:285-95.

2. Scalone L, Cortesi PA, Ciampichini R, Belisari A, D'Angiolella LS, Cesana G, et al. Italian population-based values of EQ-5D health states. Value Health. 2013;16(5):814-22.

3. Badia X, Roset M, Herdman M, Kind P. A comparison of United Kingdom and Spanish general population time trade-off values for EQ-5D health states. Med Decis Mak. 2001;21:7-16. 